\title{
J(৫)
}

Received: 01.01.2020

Accepted: 09.01.2020

Published: 29.01 .2020

JOTS, 4/1, 2020: 275-279

\section{AYDIN, E. Türklerin Bilge Atası Tonyukuk, Kronik Kitap, İs- tanbul, 2019, ss. 218, ISBN: 978-605-7635-29-7}

\author{
Hulusi PoLAT \\ Malatya/Turkey \\ E-mail: hulusipolat $44 @ g$ mail.com
}

Prof. Dr. Erhan AYDiN'ın Kronik Kitap yayınlarından çıkan üçüncü kitabı olan Türklerin Bilge Atası Tonyukuk adlı eser önsöz, giriş, 6 bölüm, Tonyukuk yazıtındaki sözcüklerin konu tasnifi, sözcük dizini, kaynaklar, Tonyukuk yazıtının Türk runik harfli metni, yeni Türk harflerine aktarımı ve günümüz Türkçesine çevirisi, yazıtın Türk runik harfli metninin tamamı, yazıta ait çizimler, fotoğraflar ve indeksten oluşmaktadır.

Eserin Önsöz (s. 7-8) bölümünde Türk runik harfleriyle yazılmış metinler ve kitabın içeriği hakkında genel bilgiler verilmiştir.

Giriş (s. 9-14) bölümünde Türk runik harfleri hakkında genel bilgiler yer almaktadır. Okuyucunun Tonyukuk yazıtını özgün metninden okuyabilmesi için yazıtta kullanılan Türk runik harflerinin ses karşılıkları tablo halinde verilmiştir. Tabloda harflerin diğer yazıtlarda kullanılan farklı biçimlerine yer verilmemiştir. Ayrıca yazıtların bulunuşu, okunuşu ve bilim dünyasına tanıtılması hakkında genel bilgilendirme yapılmıştır. 


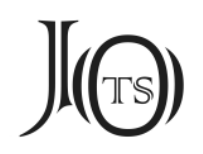

Tonyukuk ve Yazıtı ile İlgili Yapılan Çalışmalar (s. 15-28) bölümünde W. RADLOFF'un ilk yayımından başlanılarak kronolojik olarak günümüze kadar yapılmış olan 64 önemli çalışmanın bibliyografik bilgisi yer almaktadır.

Tonyukuk Kim? (s. 29-54) bölümünde Tonyukuk yazıtı, Türk runik harfli eski Türk yazıtları ve Tang Hanedanlığı dönemi Çin kaynaklarından yararlanarak Tonyukuk'un kimliği hakkında ayrıntılı bilgiler verilmiştir. Tonyukuk'un kim olduğu konusu hem Türkologların hem de Sinologların ilgisini çektiği belirtilerek Tonyukuk'un doğum tarihi hakkında araştırmacıların görüşlerine yer verilmiş ve kaynaklardan hareketle doğum tarihi belirtilmiştir.

Bazı araştırmacıların A-schi-tö Yüan-tschön (Ashide Yuanzhen) ile Tonyukuk'un aynı kişi olduğunu ileri sürdüğünü belirten yazar, Çin kaynaklarının verdiği bilgilerden hareket ederek bu iki şahsiyetin karşılaştırmasını yapmıştır.

Yazar, Çinlilerin Beşbalık seferlerinde Tonyukuk'un aktif rol oynadığını bildirdiklerini fakat Tonyukuk'un kendi yazıtında bu olaya değinmediğinin nedeni üzerinde durmuş, ayrıca Tang Hanedanlığı kaynaklarında Tonyukuk'un şahsiyeti hakkında geçen bilgilere yer vermiştir.

Tonyukuk'tan yüz elli yıl kadar sonra yazılmış Eski Uygur Türkçesi dönemine ait biri Türk runik, diğeri Uygur harfleriyle yazılmış iki metinde kendisi hakkında bilgi yer aldığı belirtilerek bu metinlere ve üzerinde yapılan çalışmalara yer verilmiştir.

Tonyukuk'un $A d \imath$ (s. 55-68) bölümünde adın anlamı ve kökeni üzerine durulmuştur. Yazar, Türk runik harflerinin /o/ ve /u/ ile /ö/ ve /ü/ ünlülerini birbirinden ayırt edecek bir sisteme sahip olmamasından kaynaklanan nedenle araştırmacılar tarafından Tonyukuk veya Tunyukuk biçimlerinde okunduğunu belirtmiştir.

Bu bölümde R. Giraud, V. M. NAdAlyayev, S. G. Klyaștorniy, O. F. SertKaya, J. P. Roux gibi araştırmacıların Tonyukuk ismi hususunda öne sürdüğü farklı anlamlandırma görüşlerine yer verilmiștir. Tonyukuk sözcügünün Tonyukuk, Bilge Kağan, Küli Çor yazıtlarında geçtiği belirtilmiştir. Sözcüğün Bilge Kağan ve Küli Çor yazıtlarında /n/ ve /y/ harfleriyle, Tonyukuk yazıtında ise /ń/ sesini gösteren 


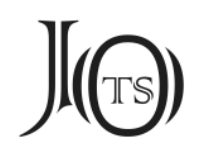

harfle yazıldığına dikkat çekilerek /ń/ sesi ile ilgili yapılan çalışmalara yer verilmiştir.

Tonyukuk'un Unvan ve Görevleri (s. 69-83) bölümünde Tonyukuk'un kullandığı unvanlar yazıtlardan hareketle tespit edilerek açıklamalarda bulunulmuş, ayrıca bu unvanlarla ilgili diğer araştırmacıların görüşlerine de yer verilmiştir. Tonyukuk ile ilgili unvanların arka arkaya sıralanmasının Türkçenin unvan grubu yapısıyla farklılı̆̆ına değinilmiştir.

Tonyukuk'un II. Köktürk Devleti'nde hangi görevlerde bulunduğu tespit edilmeye çalışılmış ve görevlerini belirleyen sözcükler üzerine açılamalar yapılmıştır. Sözcüklerin araştırmacılar tarafından farklı okunuş ve anlamlandırmalarına yer verilmiş, morfolojik yapıları üzerine durulmuş, sonraki dönem metinlerinde geçen anlamlarıyla karşılaştırmalar yapılmış, tarihi süreçte anlam değişmelerine yer verilmiş, farklı bakış açıları sunulmuştur.

Birçok kaynakta vezir olarak gösterilen Tonyukuk'un bu görevde olup olmadığı tartışmasını açan yazar; kağan, yabgu, şad unvanları ve bu unvanların kimlere verildiği konusunda ayrıntılı bilgiler vermiştir.

Tonyukuk'un Yazıtı (s. 85-92) bölümünde yazıtın Bilge Kağan ve Köl Tegin yazıtlarıyla birlikte 'Orhon/Orhun Yazıtları/Abideleri' olarak anıldığı, aralarındaki uzaklık nedeniyle bu durumun doğru olmadığı vurgulanmıştır. II. Köktürk Devleti kağanlık mücadelesinde Tonyukuk'un oynadığı rol ve sonuçları hakkında bilgilendirme yapılmıştır.

Yazıtın iki taştan oluştuğu, kaplumbağa kaide üzerine oturtma geleneğine uyulmadığı belirtilmiştir. Ayrıca yazıtın boyutları ve satırları hakkında sayısal bilgiler verilmiştir. Yazıtı bulan ve üzerinde ilk çalışmayı yapan kişiler verildikten sonra bilimsel yayınlar hakkında bilgi verilmiştir. Tonyukuk yazıtının kim veya kimler tarafından ve ne zaman yazıldığı hususunda araştırmacıların görüşlerine yer verilmiştir. Yazıttaki ifadelerden yola çıkılarak Tonyukuk'un bu yazıtı niçin yazdırdığı hususunda çıarımda bulunulmuştur. Tonyukuk yazıtının 1. taşında yer alan damga hususunda açılkamalar yapılmıştır.

Tonyukuk Yazıtında Neler Anlatılmıştır? (s. 93-140) bölümünde toplamda iki taş, sekiz cephe ve altmış iki satırdan oluşan, Köktürklerin ikinci döneminden 


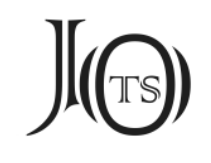

bahseden Tonyukuk yazıtı ayrıntılı olarak işlenmiştir. CLAUSON'un yazıtı on bir bölüm halinde başarılı bir şekilde başlıklandırdığı belirtilmiş ve bölüm isimleri şu şekilde verilmiştir:

1. Bölüm: (1. satır) Tonyukuk'un çocukluğu ve gençliği

2. Bölüm: (2-4. satır) Akim kalmış ayaklanma

3. Bölüm: (4-6. satır) İlteriş'in başarılı ayaklanması

4. Bölüm: (7-11. satır) Yin-shan bölgesinden göçmeden önceki olaylar

5. Bölüm: (12-15. satır) Ötüken ( Hanghai) dağlarına göç

6. Bölüm: (15-17. satır) Oğuz’a boyun eğdirilmesi

7. Bölüm: (18-19. satır) “Shantung”a akınlar

8. Bölüm: (19-29. satır) Kırkız'a boyun eğdirilmesi

9. Bölüm: (29-43. satır) On Ok (Batı Türkleri) ve Türgeş'e sefer

10. Bölüm: (43-47. satır) Demir Kapı Seferi

11. Bölüm: (48. satırdan sonuna kadar) İlteriş Kağan'ın kahramanlıkları ve Tonyukuk'un ona ve haleflerine hizmeti.

I. taşta Tonyukuk'un kendisini takdim ederek başladığı ve bağımsızlık için göstermiş olduğu mücadeleleri, kağan seçme ve şad danışmanlığı gibi görevlerine değinilmiştir. Ayrıca, sir, ülüg, böyre-, çugay yış, kordanta, kök öy, ingek kölek, tugla, taloy ügüz, ak termel, ıwırbaş, anı, yelme gibi birçok sözcük hakkında açıklamalar yapılmış, diğer araştırmacıların görüş ve okuyuşlarına yer verilmiştir.

Yazıtta geçen mecazi ifadeler açılanarak yazıtın edebî diline ve Türkçenin sekizinci yüzyıldaki ifade gücü vurgulanmıştır.

II. taşta geçen kahramanlık belirten olağanüstü ifadeler, başarı elde etmede inanç boyutuna temas eden sözcükler, Türklerin savaş kültürünü anlatan bilgiler, Tonyukuk'un kendini ifade ettiği ve övdüğü cümleler üzerinde durulmuştur.

Tonyukuk Yazıtındaki Sözcüklerin Konu Tasnifi (s. 141-145) bölümünde 21 yer adı, 14 kavim ve boy adı, 18 unvan, 17 kişi adı tasnif edilmiştir. 


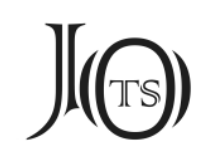

Tasnif bölümünden sonra 380 kelimelik sözcük dizini (s. 147-159), 246 yerli ve yabancı kaynaktan oluşan zengin bir kaynakça (s. 161-173) yer almaktadır. Kaynakçadan sonra Tonyukuk yazıtının Türk runik harfli metni, yeni Türk harflerine aktarımı ve günümüz Türkçesine çevirisi bir arada verilmiştir. (s. 175-189) $\mathrm{Bu}$ yöntemle yazar eserin kullanışlılığına olumlu katkı sunmuştur. Ayrıca yazıtın sadece Türk runik harfli metni de verilmiştir. (s. 191-197) Eserin sonunda yazıta ait çizim ve fotoğraflar (s. 199-211) ve indeks yer almaktadır (s. 213-218).

Türklerin Bilge Atası Tonyukuk kitabıyla Tonyukuk'un Türk kültür ve tarihine katkıları olan Türk büyükleri arasında yer aldığına şüphe bırakmamaktadır. Kitap bugüne kadar Tonyukuk ve yazıtı ile ilgili bildiğimiz bazı bilgileri sorgulaması ve tarihî kaynaklardan hareketle yeni fikirler sunması bakımından önemli bir yere sahiptir. Prof. Dr. Erhan AYDiN'ın diğer eserleri gibi bu eserinin de Türk tarihi ile Türk dili araştırmalarına ilgi duyanların yararlanacağı kaynak kitap olacağında kuşku bulunmamaktadır. 